\title{
UVC Light Simulation for Room Disinfection System
}

\author{
Nathan Raj A/L R. Ropathy ${ }^{1}$, Hui Leng Choo ${ }^{1,{ }^{*}}$, Chai Hong Yeong ${ }^{2}$, and Yin How Wong $^{2}$ \\ ${ }^{1}$ School of Computer Science and Engineering, Taylor's University, No. 1 Jalan Taylor's, 47500 \\ Subang Jaya, Malaysia \\ ${ }^{2}$ School of Medicine, Taylor's University, No. 1 Jalan Taylor's, 47500 Subang Jaya, Malaysia
}

\begin{abstract}
Viruses are minuscule parasites that have gained notoriety for causing diseases. However, these harmful pathogens can be inactivated using Ultraviolet-C (UVC) radiation that has a wavelength between $200-$ $280 \mathrm{~nm}$. The wavelengths of the UVC are responsible for germicidal effect as the proteins (e.g. RNA and DNA) absorb the maximum radiation in these wavelengths and damage the DNA of the viruses so that they cannot replicate. This project aimed to simulate the UVC light intensity in different room layouts to guide the evaluation of the effectiveness of surface disinfection system which consists of UVC lights. Besides determining the quantity and the installation layout of the UVC lights, the project also aimed to help visualisation of the coverage of UVC radiation and highlight any under-exposed area for optimum room disinfection using a simulation software. DIALux Evo 9.1 was used to simulate the light intensity in different room and lighting layouts. As the software only calculates normal visible light (wavelength $380-700 \mathrm{~nm}$ ) intensity in the unit of Lux, a correlation between Lux and UVC dosage $(\mathrm{mJ} / \mathrm{cm} 2)$ must be established first. A minimum UVC dosage of $40 \mathrm{~mJ} / \mathrm{cm} 2$ is required to achieve complete surface disinfection of microorganisms. The simulation was able to visualize the coverage of UVC radiation and to determine the optimum placement of UVC lights to ensure sufficient UVC dosage is delivered to every critical surface. The outcome of this project can help to guide the design of UVC room disinfection system especially in hospital wards setting to optimise room disinfection and reducing the risk of infection.
\end{abstract}

\section{Introduction}

Harmful pathogens can be inactivated using Ultraviolet-C (UVC) surface disinfection method. UVC is a type of electromagnetic radiation that has the wavelength between 100 and $280 \mathrm{~nm}$. The other two types of UV radiation are UVA $(315-400 \mathrm{~nm})$ and UVB) $(280$ $-315 \mathrm{~nm}$ ) [1]. The shorter the wavelength the more energetic the radiation. This can be explained by Planck's equation, $\mathrm{E}=\mathrm{h} \times v$, where $\mathrm{E}$ is the energy $(\mathrm{J}), \mathrm{h}$ is the Planck's constant $\left(6.626 \times 10^{-34} \mathrm{~J} . \mathrm{s}\right)$ and $v$ is the frequency $\left(\mathrm{s}^{-1}\right)$. While UVA and UVB may arrive to

\footnotetext{
* Corresponding author: huileng.choo@taylors.edu.my
} 
the earth from the sunlight or outer space, UVC is completely absorbed by the ozone layer before reaching the earth. Hence, the source of UVC can only be artificially produced, such as from a low-pressure mercury lamp or LED lamps. The most effective germicidal wavelength occurs at the peak of 250 to $270 \mathrm{~nm}$ at which DNA absorbs UVC the most and UVC lamps can be designed to produce these specific wavelengths [2, 3]. The UVC light from the first invention of the lamps was initially used for water treatment to disinfect the pathogens. Over the decades, these inventions have further advanced in creating various alternative methods of disinfecting pathogens, such as air disinfection and surface disinfection which uses the UVC lamps.

UVC radiation is particularly effective at disinfection. Specifically, the wavelength of $254 \mathrm{~nm}$ is the most effective at killing germs, viruses and bacteria [4]. UVC radiation can travel through air without creating ozone, therefore UVC lights can be utilized in the room to disinfect surfaces. Hence, UVC radiation plays an important role in preventing infectious diseases, such as the COVID-19. The application of UVC is more commonly used in hospital rooms and wards to disinfect bacteria, viruses and other microorganisms. The minimum UVC dose required for surface disinfection is $40 \mathrm{~mJ} / \mathrm{cm}^{2}$ [5]. It is important to note that the time of irradiation or the time take to disinfect the microorganisms(s) and irradiance $\left(\mu \mathrm{W} / \mathrm{cm}^{2}\right)$ are needed to quantify the dose for the deactivation of microorganisms. One of the challenges faced during the application of UVC is the coverage area of UVC radiation. The hospital authorities have limited knowledge if all the areas were exposed to UVC radiation adequately and therefore unsure if the area has been completely disinfected. There is also very little publication on this area. This project used the DIALux Evo 9.1 software to simulate different room layouts to determine the number and placement of UVC lamps, as well as the duration of UVC irradiation so that all the under-exposed areas can be covered by a minimum UVC dosage of $40 \mathrm{~mJ} / \mathrm{cm}^{2}$.

\section{Methodology}

\subsection{UVC light simulation}

The simulation of UVC light intensity was carried out using DIALux Evo 9.1 by DIAL $\mathrm{GmbH}$, Germany. Using the software, the dimensions of a physician's consultation room was firstly created according to the recommended hospital room dimensions provided by the Ministry of Health Malaysia [6], as shown in Table 1. The apertures and the furniture in the room were added to replicate a real-life hospital consultation room. Other factors such as the space clearances, bed space, and the door space have been considered into the room dimensions. The UVC lights were positioned at different positions in the room to understand the effects on the UVC intensity in the room.

Table 1. Dimensions of rooms set-up in DIALux Evo 9.1.

\begin{tabular}{|c|c|c|c|}
\hline Room Type & Length $(\mathbf{m})$ & Width $(\mathbf{m})$ & Height $(\mathbf{m})$ \\
\hline Consultation & 5 & 4 & 3 \\
\hline
\end{tabular}

The room simulation was started with two UVC lights (Philips Germicidal UVC, $4 \mathrm{ft}$, $36 \mathrm{~W}$ ) placed on the ceiling arranged in series as shown in Figure 1. The distance between the lights was set to $1 \mathrm{~m}$ apart. The simulation was run to obtain the UVC intensity distribution in the room. 


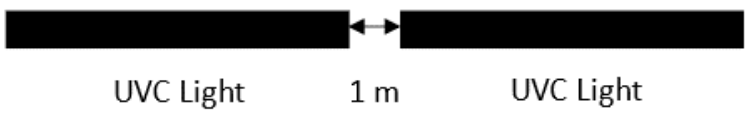

Fig. 1. UVC lights arrangement for the simulation of a consultation room.

\subsection{Determination of Lux to UVC dosage conversion factor}

The DIALux Evo software is very useful in determining light intensity under different scenarios. However, the values obtained from the simulation is in the unit of Lux (lx) which is a common unit used for fluorescent or visible light. In order to investigate the relationship between Lux and UVC intensity in $\mu \mathrm{W} / \mathrm{cm}^{2}$, an experiment was carried out to determine the Lux to $\mu \mathrm{W} / \mathrm{cm}^{2}$ conversion factor. The experiment was carried out under a controlled environment in a room with dimensions $4 \times 4 \times 3 \mathrm{~m}$. It was ensured that no reflective materials that could affect the result were used or present in the room at the time of the experiment. The surface of the walls are made up of plaster, which only subject to diffusive reflection. Diffusive reflection is a light reflection from a surface such that the incident ray is reflected at many angles, rather than just one angle like a mirror. Therefore, this would not cause any significant effect on the luminance measurement [7]. A total irradiation time of $90 \mathrm{~s}$ (warm-up time of $30 \mathrm{~s}$ and a response time of $60 \mathrm{~s}$ ) was given at the beginning of each cycle of measurement before the final reading was taken. A $120 \mathrm{~cm}$ Philips Germicidal UVC light that has an output power of $36 \mathrm{~W}$ was used in this experiment. A Lux meter was used to obtain the readings in Lux unit and a UVC meter was used to measure the UVC intensity in $\mu \mathrm{W} / \mathrm{cm}^{2}$. The experiments were carried out by varying the distance perpendicular to the UVC lamp and parallel along the length of the UVC lamp.

\subsubsection{First arrangement: Varying the perpendicular distance}

The Lux meter and the UVC meter were placed on the ground in a fixed position side by side as shown in Figure 2. The UVC lamp was placed in a position such that the two meters are in the middle of the bulb. The UVC lamp was moved perpendicularly along five distances from $1-5 \mathrm{ft}$. Once the UVC light is turned on, the readings for light using the Lux meter and the UVC exposure through the UVC meter were recorded after $90 \mathrm{~s}$. The experiment was repeated for a total of five times in each distance.

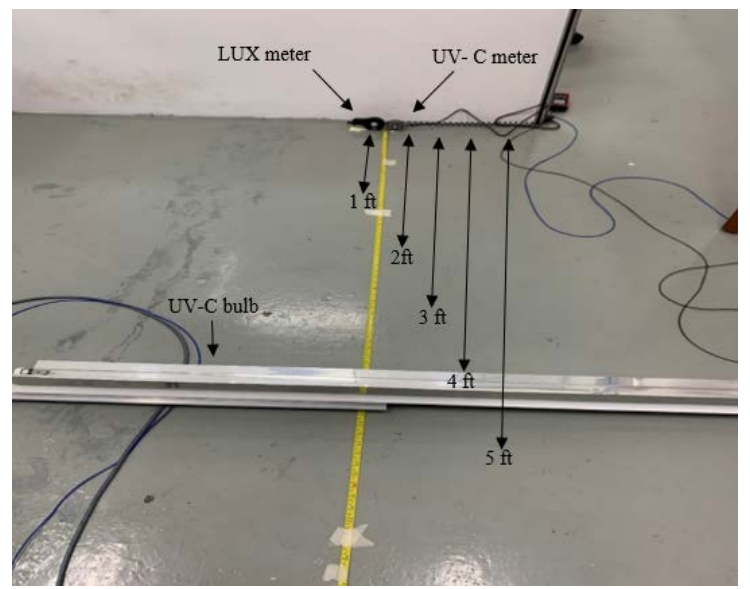

Fig. 2. First arrangement: UVC bulb and the two meters used to record the light and UVC capacity. 


\subsubsection{Second arrangement: Varying the parallel distance}

The Lux meter and the UVC meter were placed on the ground in a side by side position as shown in Figure 3. The UVC lamp was placed in a fixed position $1 \mathrm{ft}$ away from the two meters. The Lux meter and the UVC meter were moved along the five points that were set along the length of the UVC lamp, where the $1^{\text {st }}$ point corresponds to the origin, the $2^{\text {nd }}$ point corresponds to $1 \mathrm{ft}$ from the origin and so on until the $5^{\text {th }}$ point, corresponding to $4 \mathrm{ft}$ from the origin. The distance between the UVC lamp and the two meters were kept at $1 \mathrm{ft}$ until all readings were taken. Subsequently, the experiment was repeated by increasing the distance between the UVC lamp and the two meters to $2-5 \mathrm{ft}$. Once the UVC light was turned on, the readings from the Lux meter and the UVC meter were recorded after $90 \mathrm{~s}$. The experiment was repeated for a total of five times at each of the five points.

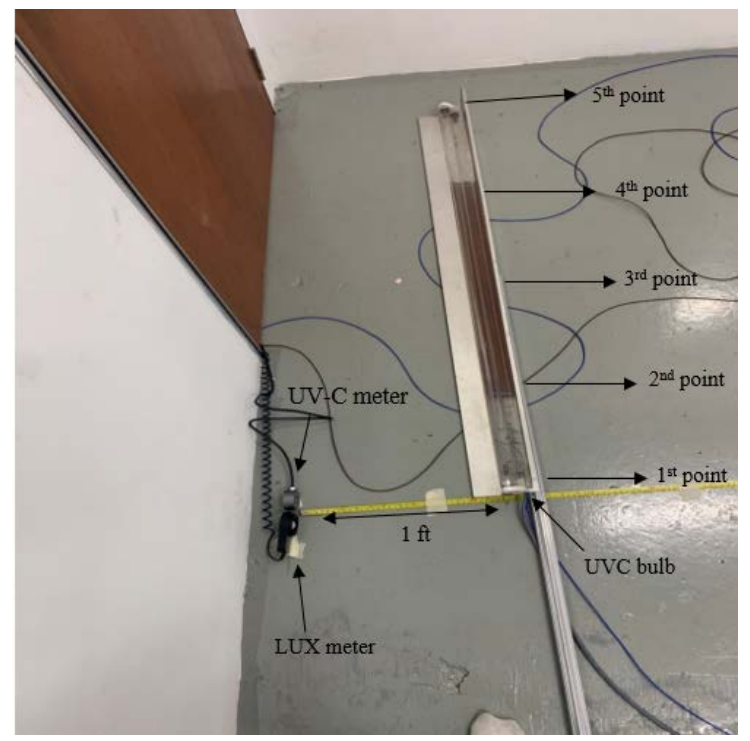

Fig. 3. Second arrangement: The UVC and Lux meters were placed at $1 \mathrm{ft}$ away from the UVC bulb for the $1^{\text {st }}$ point.

\section{Results and Discussion}

\subsection{Lux to UVC intensity conversion factor}

Table 2 shows all the results obtained from the experiments, which is plotted and displayed in Figure 4. In general, as predicted, both Lux intensity and UVC intensity decreased with increasing distance from the UVC light source. In addition, both intensities also decreased with an increasing angle from the mid-point of the UVC lamp.

There is a good linear correlation between UVC intensity $\left(\mu \mathrm{W} / \mathrm{cm}^{2}\right)$ and Lux intensity (Lx) as shown in Figure 4. The relationship between UVC intensity and Lux intensity can be approximated using a linear least square line as shown by Equation 1 . The $\mathrm{R}^{2}$ obtained is 0.9456 , indicating a strong correlation between the two variables. The conversion factor is obtained as $4.64 \mu \mathrm{W} / \mathrm{lx}^{-\mathrm{cm}^{2}}$.

$$
\text { UVC Intensity }\left(\mu \mathrm{W} / \mathrm{cm}^{2}\right)=4.64 \times \text { Lux Intensity }
$$

To convert Lux intensity to UVC dosage, in $\mathrm{mJ} / \mathrm{cm}^{2}$, Equation 2 is used. 
UVC Dosage $\left(\mathrm{mJ} / \mathrm{m}^{2}\right)=$ UVC Intensity $\left(\mu \mathrm{W} / \mathrm{cm}^{2}\right) \times$ Exposure Duration $(\mathrm{s})$

Table 2. The average values measured for the first and the second arrangement.

\begin{tabular}{|c|c|c|c|c|}
\hline Arrangement & $\begin{array}{c}\text { Perpendicular } \\
\text { distance (ft) }\end{array}$ & $\begin{array}{c}\text { Parallel } \\
\text { distance (ft) }\end{array}$ & $\begin{array}{l}\text { Average } \\
\text { Lux (lx) }\end{array}$ & $\begin{array}{c}\text { Average UVC } \\
\left(\mu \mathrm{W} / \mathrm{cm}^{2}\right)\end{array}$ \\
\hline \multirow{5}{*}{$\begin{array}{l}\text { First } \\
\text { arrangement }\end{array}$} & 1 & \multirow{5}{*}{$\begin{array}{l}\text { Middle of the } \\
\text { UVC bulb }\end{array}$} & 159.60 & 848.02 \\
\hline & 2 & & 71.60 & 419.52 \\
\hline & 3 & & 41.20 & 239.36 \\
\hline & 4 & & 26.20 & 147.78 \\
\hline & 5 & & 19.80 & 100.42 \\
\hline \multirow{25}{*}{$\begin{array}{l}\text { Second } \\
\text { arrangement }\end{array}$} & \multirow{5}{*}{1} & 0 & 80.00 & 334.90 \\
\hline & & 1 & 138.40 & 714.86 \\
\hline & & 2 & 146.80 & 798.56 \\
\hline & & 3 & 127.60 & 730.60 \\
\hline & & 4 & 55.60 & 357.02 \\
\hline & \multirow{5}{*}{2} & 0 & 95.48 & 218.84 \\
\hline & & 1 & 119.18 & 339.42 \\
\hline & & 2 & 105.90 & 385.82 \\
\hline & & 3 & 94.86 & 343.76 \\
\hline & & 4 & 59.58 & 216.38 \\
\hline & \multirow{5}{*}{3} & 0 & 33.72 & 159.40 \\
\hline & & 1 & 43.00 & 220.12 \\
\hline & & 2 & 48.58 & 249.60 \\
\hline & & 3 & 49.66 & 236.72 \\
\hline & & 4 & 41.68 & 169.10 \\
\hline & \multirow{5}{*}{4} & 0 & 28.10 & 114.82 \\
\hline & & 1 & 33.62 & 142.30 \\
\hline & & 2 & 36.94 & 156.34 \\
\hline & & 3 & 15.52 & 154.16 \\
\hline & & 4 & 32.50 & 120.30 \\
\hline & \multirow{5}{*}{5} & 0 & 22.74 & 88.60 \\
\hline & & 1 & 24.10 & 96.76 \\
\hline & & 2 & 27.24 & 102.34 \\
\hline & & 3 & 24.70 & 98.74 \\
\hline & & 4 & 25.56 & 88.34 \\
\hline
\end{tabular}

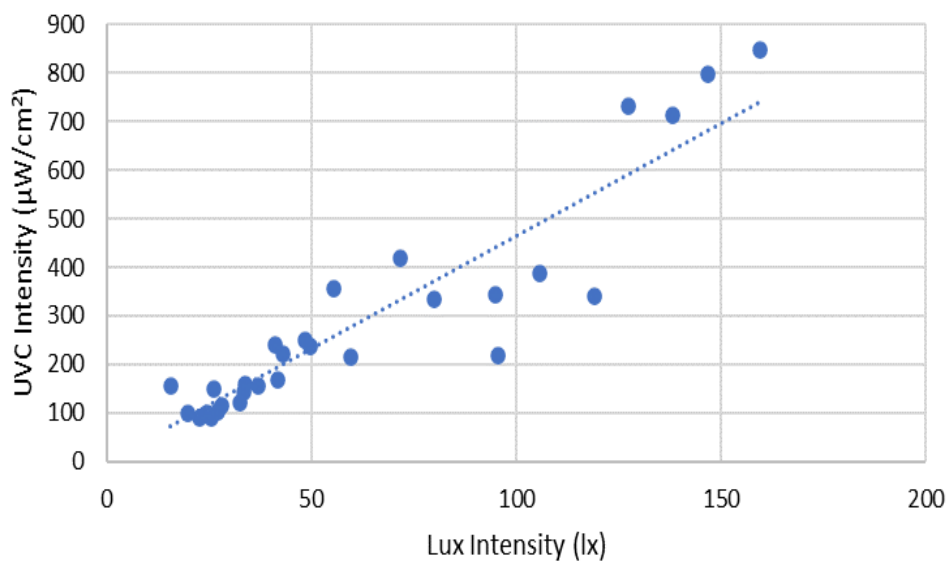

Fig. 4. Graph of UVC intensity vs Lux intensity combining all data points from Table 2. 


\subsection{Simulation results}

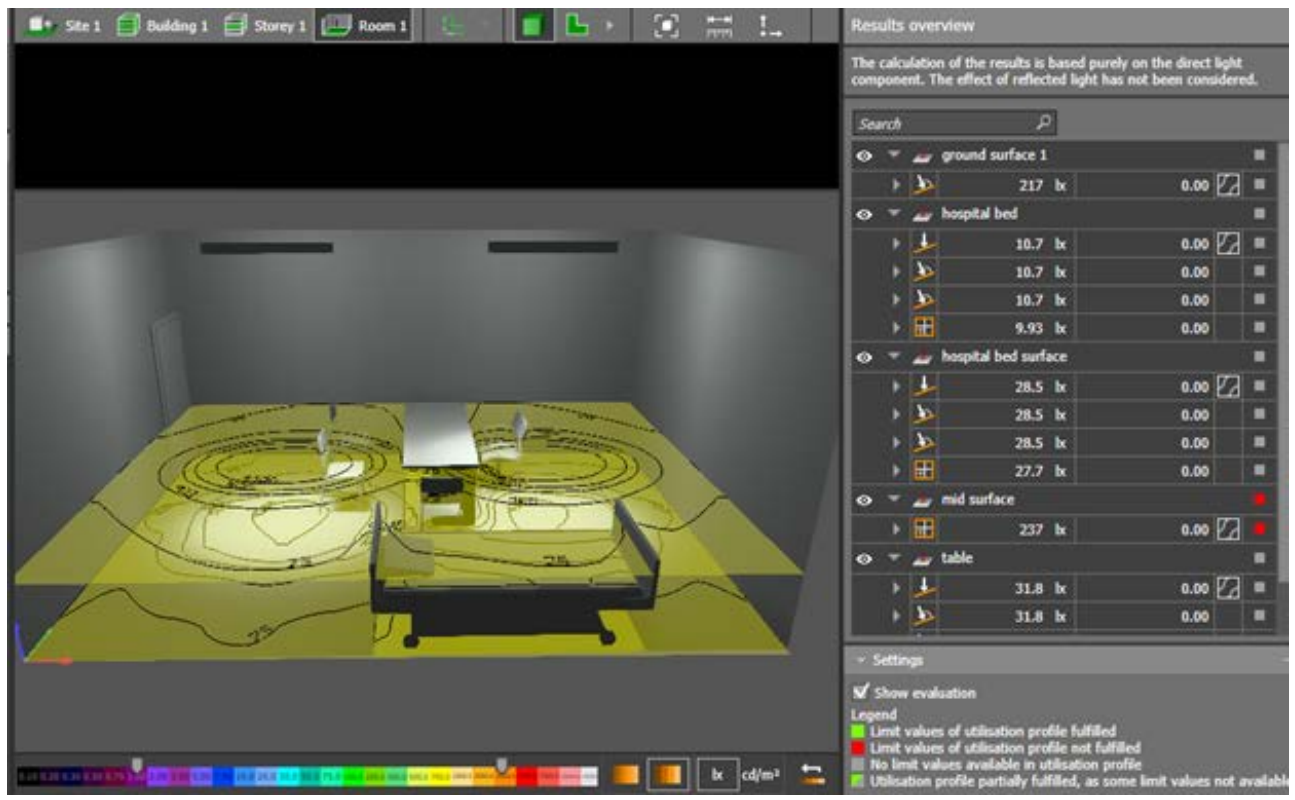

Fig. 5. Simulation results of consultation room set-up in DIALux Evo 9.1 software. Two UVC lights were positioned on the ceiling in series.

Figure 5 shows the simulation results of the consultation room. The contours show the distribution of Lux intensity in the consultation room. At the surface of the bed, the intensity is around $28.5 \mathrm{~lx}$. Using Equation 1 and 2 and an exposure duration of $90 \mathrm{~s}$, this is equivalent to a UVC dosage of $11.9 \mathrm{~mJ} / \mathrm{cm}^{2}$. This shows that $90 \mathrm{~s}$ is not sufficient for disinfection of the bed surface when using two UVC lights in the arrangement in Figure 5 because the dosage is below the recommended dosage of $40 \mathrm{~mJ} / \mathrm{mm}^{2}$. For complete disinfection, the exposure duration should be increased to at least $302 \mathrm{~s}$ to achieve a UVC dosage of $40 \mathrm{~mJ} / \mathrm{cm}^{2}$.

\section{Conclusions and Future Work}

Based on the preliminary results obtained, it can be concluded that simulation using DIALux Evo software can be used to determine the optimum exposure duration and UVC light arrangement for the room disinfection. With the conversion factor of Lux intensity to UVC intensity obtained experimentally, the output from the simulation can be converted into UVC intensity and finally UVC dosage (by multiplying the exposure time) to determine whether sufficient UVC dosage has been reached. In the future, this project will cover different types of hospital wards settings such as single-bedded and double-bedded ward, as well as optimising the quantity and the arrangement of UVC lights to be used in each room type.

\section{References}

1. J. Z. Beer, K. M. Olvey, S. A. Miller, D. P. Thomas, D. E. Godar, Photochem. Photobiol., 58, 676 (1993)

2. G. D. Harris, V. D. Adams, D. L. Sorensen, M. S. Curtis, Water Res., 21, 687 (1987) 
3. S. J. Kim, D. K. Kim, D. H. Kang, Appl. Environ. Microbiol., 82, 11 (2016)

4. A. Renzel, Disinfection with UVC (uv-technik meyer GmbH, 2016)

5. Advice for the selection and operation of equipment for the UV disinfection of air and surfaces, (International Ultraviolet Association (IUVA), 2020)

6. Handbook on Setting Up of Private Hospitals in Malaysia, (Private Medical Practice Control Division (CKAPS), 2019)

7. A. K. R. Choudhury, Principles of colour and appearance measurement: Object appearance, colour perception and instrumental measurement (Elsevier, 2014) 